\title{
PROPOSTA DE IMPLEMENTAÇÃO DE ESTRATÉGIAS PARA CAPTAÇÃO DE RECURSOS NAS ORGANIZAÇÕES SEM FINS LUCRATIVOS: ESTUDO DE CASO LAR BATISTA JANELL DOYLE
}

\section{ARTIGO ORIGINAL}

MARTINS, Kelly Teixeira ${ }^{1}$, CHAVES, Ely Printes ${ }^{2}$, SILVA, Rayanne Cristina Ayres $\mathrm{da}^{3}$, ROBERTO, José Carlos Alves ${ }^{4}$

MARTINS, Kelly Teixeira. Et al. Proposta de implementação de estratégias para captação de recursos nas organizações sem fins lucrativos: estudo de caso Lar Batista Janell Doyle. Revista Científica Multidisciplinar Núcleo do Conhecimento. Ano. 06, Ed. 10, Vol. 06, pp. 144-167. Outubro 2021. ISSN: 24480959, Link de acesso:

https://www.nucleodoconhecimento.com.br/administracao/implementacao-deestrategias, DOI:

10.32749/nucleodoconhecimento.com.br/administracao/implementacao-deestrategias

\section{RESUMO}

O presente artigo tem o propósito de apresentar uma solução para a problemática que se manifestou a partir da realização do Diagnóstico Organizacional no abrigo Lar Batista Janell Doyle, localizada na cidade de Manaus. Como objetivo geral, procurou-se organizar um plano de ação para que o segmento financeiro melhorasse seu rendimento, propondo ideias que poderiam maximizar os resultados operacionais. Este estudo tem como questão norteadora: como a captação de recursos pode colaborar com as organizações sem fins lucrativos? Para isto, foram

\footnotetext{
${ }^{1}$ Graduando do curso de Administração.

${ }^{2}$ Graduando do curso de Administração.

${ }^{3}$ Graduando do curso de Administração.

${ }^{4}$ Orientador. Mestrado profissional em Engenharia de produção. Especialização em Gestão em Logística empresarial. Graduação em Administração com Ênfase em Marketing.
}

RC: 99485

Link de acesso:

https://www.nucleodoconhecimento.com.br/administracao/implementacao-deestrategias 
expostas ideias sobre a administração contábil, retratando suas perspectivas e finanças, ressaltando também a importância do processo financeiro para a manutenção do local. Esta pesquisa foi construída por intermédio do apoio de obras de caráter analítico quali-quantitativo, utilizando-se, quantos aos fins, a pesquisa exploratória. No que concerne à metodologia e aos meios, pautou-se principalmente na pesquisa de campo. A partir da análise dos dados da investigação, a equipe alcançou, por conseguinte, uma visão mais clara do que de fato é fundamental para aprimorar o segmento de finanças da entidade proposta no estudo. Deste modo, foi utilizado a ferramenta $5 \mathrm{~W} 2 \mathrm{H}$, onde foi possível constatar algumas implementações para captação de recursos, tais quais: o início de um setor de telemarketing, a oferta de uma jornada científica, exposições de um brechó simbólico, além de outras reuniões que proporcionassem um evento beneficente. Com isso, esperamos que o setor financeiro, possua um rendimento inicial satisfatório para prover a precisão do problema exposto.

Palavras-Chave: Administração financeira, planejamento, instituição.

\section{INTRODUÇÃO}

A proposta de solução para esse estudo de caso surgiu a partir do Diagnóstico Organizacional realizado no abrigo Lar Batista Janell Doyle, o qual desempenha serviços de acolhimento institucional voltado para crianças e adolescentes em situações de risco, além de serviços de convivência e fortalecimento de vínculos com famílias da comunidade e abordagem social para moradores de rua na cidade de Manaus.

Através do diagnóstico efetuado, a equipe verificou que o abrigo proposto no estudo demonstra ter uma grande falha, ou até mesmo carência, no setor financeiro, tendo visto que esta ainda apresenta grande déficit operacional em seus procedimentos, embora seja de fundamental importância para a manutenção do abrigo. Com isso, seria necessária a adaptação de seus processos, principalmente nos pontos que

RC: 99485

Link de acesso:

https://www.nucleodoconhecimento.com.br/administracao/implementacao-deestrategias 
concernem ao fluxo de caixa. Ressalta-se que, com o decorrer das visitas técnica e do desenvolvimento da pesquisa, tal fluxo apresentou grandes distorções - reflexo do somatório de arrecadações colhidas até o final do mês, as quais demonstram que o abrigo não possui os resultados necessários para atender as demandas do Lar, o que vem causando preocupações para os envolvidos. Deste modo, a pergunta problema consiste em: Como a captação de recursos pode colaborar com as organizações sem fins lucrativos?

A partir desse contexto, houve a necessidade de propor melhorias para o setor financeiro do local, sugerindo-se maneiras pelas quais poderiam ser feitas captações de recursos, aderindo-se a algumas implementações, tais quais: o início de um setor de telemarketing, a oferta de uma jornada científica, exposições de um brechó simbólico, além de outras reuniões que proporcionassem um evento beneficente. Desta forma, ilustrar tais pontos poderiam ser de suma importância para fazer com que o segmento financeiro do Lar construísse gradativamente um levantamento inicial positivo, de modo a suprir com as necessidades em questão.

No que se refere à comunidade acadêmica, este estudo possui o intuito de contribuir com conhecimentos do assunto de fluxo contábil abordado, estimulando pesquisas sobre intervenções no segmento financeiro de instituições semelhantes, bem como a propositura de soluções para problemáticas de caixa, além de prover maiores entendimentos científicos para a formação das autoras.

\section{FUNDAMENTAÇÃO TEÓRICA}

A fundamentação teórica trata-se de um estudo aprofundado em publicações equivalentes a uma área de estudo, com o propósito de obterem-se as respostas ou maiores informações sobre o ramo analisado.

Para Vergara (2015), designa-se referencial bibliográfico um conjunto de conhecimentos sobre o tema, levantamento dos conceitos que serão abordados na pesquisa ou uma compreensão do que foi produzido no assunto.

RC: 99485

Link de acesso:

https://www.nucleodoconhecimento.com.br/administracao/implementacao-deestrategias 
Segundo Walliman (2015), o levantamento bibliográfico é referente ao tema que já foi produzido por outros pesquisadores ou que descreveu o problema. Para isso, é necessário citar autores que estão por dentro dos assuntos em discussão.

A fundamentação teórica apresenta a coleta e análise de dados nos quais se baseia a pesquisa, consistindo nas revisões de artigos, livros e todo o material pertinente do ramo ou do assunto estudado (COOPER; SCHINDLER, 2016).

\subsection{ADMINISTRAÇÃO E SUAS PERSPECTIVAS}

Atualmente, a Administração é reconhecida como uma das mais importantes áreas das organizações e de atividade humana, ou seja, administrar tem como processo o ato de tomar, realizar e alcançar ações que possam utilizar recursos para atingir objetivos, efetuar diagnósticos e descrever situações.

De acordo com os autores Aragão e Filho (2016), a administração é realizada mediante o encontro de pessoas, por meio dos planos que já constam estabelecidos e de recursos controlados. Além de possuir as pessoas lideradas, ainda conta com atividades conduzidas e as metas a serem alcançadas.

Para Kwasnicka (2012), administrar é o processo de complementar a atividade organizacional que ocorre em nossa vida diária. A necessidade de administrar surge perante o confronto entre as variantes que compõem uma ocupação propriamente estruturada, como por exemplo: recursos materiais, humanos e tecnologia.

A administração é a atuação de tomar decisões sobre os recursos e objetivos. Contudo, explica diferentes enfoques e visões ao longo do tempo. Apesar de possuir diversos atributos, continua nos esforços para melhorar a condução da organização (MAXIMIANO, 2015).

A forma pela qual é administrada torna a organização capaz de utilizar estes recursos de forma correta. Caso apresente dificuldades e novos desafios, será

RC: 99485

Link de acesso:

https://www.nucleodoconhecimento.com.br/administracao/implementacao-deestrategias 
utilizado uma teoria administrativa que ofereça modelos e estratégias adequadas para a solução dos problemas propostos.

\subsection{FINANÇAS}

O termo "finanças" está associado à economia, área na qual são estudados os investimentos, a aplicação de capital, o conjunto de recursos disponíveis circulantes em espécie usados em transações, além de negócios com a expectativa de benefício futuro.

O estudo de finanças interpreta o registro e análise da vida econômica das empresas, as metas a serem alcançadas em certo prazo, o gerenciamento da fonte de renda e a aplicação em investimentos capazes de captar recursos para sustentálas (BRIGHAM; EHRHARDT, 2016).

Para Gitman (2010), finanças trata-se do processo, instituições ou mercados que possuam envolvimento com o deslocamento de dinheiro entre pessoas, empresas e órgãos governamentais. Contudo, o campo "finanças" é bastante abrangente, afetando nossas vidas e organizações.

Segundo Oliveira (2016), de modo geral, os indivíduos e organizações estão sempre comprometidos com atividades financeiras, uma vez que recebem, levantam, gastam e investem dinheiro de modo contínuo.

\subsection{A IMPORTÂNCIA DA GESTÃO FINANCEIRA}

Para obtenção de resultados positivos através da gestão financeira, é preciso ter uma visão estratégica do negócio, de modo a evitarem-se problemas atuais e futuros dentro da organização. É necessário um bom controle financeiro para analisar o gerenciamento do fluxo de caixa, além da verificação e planejamento das ferramentas a serem utilizadas durante todo o acompanhamento do cotidiano, seja no processo empresarial, seja no planejamento orçamentário.

RC: 99485

Link de acesso:

https://www.nucleodoconhecimento.com.br/administracao/implementacao-deestrategias 
Segundo Santana (2013), compreende-se a gestão das finanças de organizações e empresas através de documentos que apresentem um conjunto de informações das atividades realizadas e de resultados coletados junto ao fluxo de caixa de forma exata.

O controle financeiro é de grande interesse nos processos administrativos, na possibilidade de alcançar metas. O responsável pela gestão financeira tem como grande objetivo resolver problemas do capital de giro e gerenciamento de contas (SILVA, 2015).

As organizações lucrativas e as sem fins lucrativos obtém lucros de várias atividades, mesmo que os propósitos de suas operações sejam diferentes. Ainda que uma entidade não busque lucro, é necessária uma gestão para permitir que este alcance sustentabilidade (CHIAVENATO, 2015).

\subsection{PROCESSOS FINANCEIROS}

Os processos financeiros de uma empresa são fundamentais para o crescimento estratégico de qualquer negócio. É necessário estarem bem estruturados para garantirem as normas adequadas, assertividade, distribuição e otimização do tempo das tarefas administrativas.

Para Sordi (2018), os processos financeiros de uma empresa desencadeiam a tomada de decisão mais comprovada e eficiente para aquele momento. Além de reforçar o desenvolvimento comercial da organização, acalmam os ruídos internos e, por conseguinte, reduzem erros, garantido o bem-estar financeiro para situações diversas.

Segundo Gillespie et al. (2013), os processos financeiros de uma organização influenciam não apenas a gestão, mas também a estrutura da companhia. Então, é imprescindível que sejam traçadas boas metas, concedendo a cada profissional a liberdade de encontrar o melhor caminho.

RC: 99485

Link de acesso:

https://www.nucleodoconhecimento.com.br/administracao/implementacao-deestrategias 
Além disso, é plausível que sejam traçados investimentos de aperfeiçoamento nos procedimentos da empresa, como por exemplo: melhorias na gestão de contas a pagar e a receber, de modo que sejam atendidas as demandas em seu devido prazo, auxiliando, assim, na comunicação interna e no fluxo das organizações (LIMA; NETO, 2019).

\subsection{ADMINISTRAÇÃO FINANCEIRA}

Administração financeira trata da gestão das finanças de uma organização, fortalecendo seus departamentos com artifícios essenciais ao seu bom funcionamento. Quanto melhor é a execução do planejamento financeiro, mais oportunidade de crescimento e desenvolvimento a empresa pode possuir.

Segundo Ross (2015), a grande finalidade da administração financeira é maximizar o valor das ações da empresa para escapar das crises relacionadas a diferentes escopos. Esses escopos identificam um ponto forte do qual os sócios de uma organização fazem parte.

A respeito da administração financeira, Pearson (2010) relaciona suas características aos gestores financeiros da empresa. Estes gestores são encarregados pela administração dos negócios monetários das instituições de qualquer espécie (monetárias ou não), sejam elas amplas ou estreitas, com ou sem fins lucrativos.

Neste sentido, pode-se dizer que a administração financeira é um campo de estudo conceitual e prático que possui uma finalidade, principalmente no que concerne a assegurar mais eficiência à atividade empresarial de captação de recursos de capital (SOUZA, 2014).

Percebe-se, portanto, a grande dimensão da administração financeira, que tem agregado normas visando aos procedimentos de monitoramento e planejamento para a qualidade da gestão das ferramentas contábeis da empresa.

RC: 99485

Link de acesso:

https:/www.nucleodoconhecimento.com.br/administracao/implementacao-deestrategias 


\subsection{FERRAMENTA 5W2H}

A ferramenta $5 \mathrm{~W} 2 \mathrm{H}$ é uma lista de tarefas com prazos e obrigações a serem desenvolvidas com transparência e eficácia pelos que estão incluídos no desenvolvimento do projeto. A ferramenta $5 \mathrm{~W} 2 \mathrm{~h}$ possui como propósito determinar o que será feito, porque, onde, quem irá fazer, quando será feito, como e quanto custará.

Segundo as lições de Passarle (2014), a ferramenta 5W2H é possível ser compreendida a partir do modo como dispomos o raciocínio, de uma forma bem estruturada e constituída primeiramente para implementação de qualquer resultado para o negócio.

Para o autor Lobo (2020), a 5W2H é o conjunto de ações utilizado para construir planos de maneira rápida e eficiente. Seu principal foco é estabelecer atividades convenientes, com assistência, de maneira visual, ativa e simples.

Pode-se definir a 5W2H como um instrumento administrativo que pode ser utilizado em qualquer organização. Ela é apontada como uma das técnicas mais eficazes para o planejamento de atividades, de forma que se pode garantir uma visão do plano de ação a ser executado (PALADINI, 2019).

Sendo assim, é possível concluir que a ferramenta $5 \mathrm{~W} 2 \mathrm{H}$ é tão simples e de fácil tão aprendizado que pode ser usada em diversas áreas de qualquer empresa, facilitando as definições de suas responsabilidades para tornar mais perceptível seu planejamento estratégico.

\section{MATERIAIS E MÉTODOS}

De acordo com Lakatos e Marconi (2021), a metodologia é composta por atividades sistêmicas e racionais, cujo objetivo é permitir que os conhecimentos adquiridos

RC: 99485

Link de acesso:

https://www.nucleodoconhecimento.com.br/administracao/implementacao-deestrategias 
sejam válidos, com a finalidade de serem traçados, detectados e que possam ajudar no auxílio dos materiais e métodos da pesquisa.

Para Libório e Terra (2015), o método científico é um conjunto de regulamentos que são fundamentais em uma pesquisa cientifica, tendo como finalidade alcançar suas metas com soluções viáveis, assim chegando à verdade através dos problemas ocorridos.

A Metodologia é a área em que se pratica excelentes métodos e diferentes técnicas no processo de produção do conhecimento, pois se constitui de bases teóricas da ciência. Desta forma, este trabalho aplicará diferentes técnicas para analisar os melhores métodos capazes de indicar as melhores soluções no ajustamento das dificuldades e problemas anteriormente identificados no abrigo Lar Batista Janell Doyle.

\subsection{PROCEDIMENTOS METODOLÓGICOS}

Os procedimentos metodológicos referem-se a um conjunto de técnicas a serem utilizadas na pesquisa. Este projeto ocorreu por meio de coleta e dados, com o propósito de planejar métodos e ferramentas que auxiliassem na sustentabilidade no abrigo Lar Batista Janell Doyle.

\subsubsection{QUANTO À NATUREZA}

Segundo Zanella (2013), a pesquisa quanto à natureza corresponde a duas finalidades: a básica, que trabalha na questão da melhoria do conhecimento, contribuindo para a explicação dos fenômenos, e a aplicada, que corresponde a entender os problemas humanos, cujo objetivo é lidar com o problema apresentado.

Para Appolinário (2011), a pesquisa básica corresponde ao avanço do conhecimento científico, com a aplicabilidade imediata dos resultados. Contudo, a pesquisa aplicada consiste na solução do problema apresentado de forma imediata.

RC: 99485

Link de acesso:

https://www.nucleodoconhecimento.com.br/administracao/implementacao-deestrategias 
A natureza utilizada no projeto define-se como pesquisa quali-quantitativa, pois, no primeiro momento, foi feita a análise de dados através dos formulários de pesquisas, realizando-se a coleta de dados, após a interpretação dos resultados, foram trabalhadas as problemáticas nas quais o abrigo mais necessitava de aperfeiçoamento.

\subsubsection{QUANTO AOS FINS}

Segundo Severino (2017), a pesquisa exploratória destina-se exclusivamente a elevar as investigações sobre um determinado planejamento, delimitando assim uma área de trabalho em sua sistematização sobre os argumentos de dúvidas abordados pelo artigo.

Para Pereira (2019), quanto aos fins da pesquisa, estes estão relacionados sob qualquer contexto, independente da sua tipologia. Para isso, a pesquisa pode ser exploratória, descritiva e explicativa, conforme melhor entendimento da pesquisa realizada.

Neste estudo, utilizou-se a pesquisa exploratória, obtendo-se uma melhor visão sobre a investigação, auxiliando na agilidade para finalização dos processos, com o intuito de implementar o setor de telemarketing, objetivando, por fim, a captação de recursos para a sustentabilidade da entidade.

\subsubsection{QUANTO AOS MEIOS}

De acordo com Nunes e Lozada (2018), a pesquisa quanto aos meios está relacionada à explicação do problema, buscando-se o método de solução para o caso. Para isso, foram utilizados livros e artigos da área de administração e finanças.

Para Azevedo (2013), a pesquisa quanto aos meios é aquela que está ainda em desenvolvimento para explicar um problema, sendo necessário, para melhor

RC: 99485

Link de acesso:

https://www.nucleodoconhecimento.com.br/administracao/implementacao-deestrategias 
compreensão, utilizar o conhecimento disponível, como por exemplo: obras disponíveis.

O projeto pautou-se em pesquisa de campo, investigação, coleta de dados e interpretação dos resultados obtidos, com o objetivo de reunir as informações para a construção de uma proposta concreta e realizável a médio prazo.

\subsection{CARACTERÍSTICAS DA EMPRESA}

O Lar Batista Janell Doyle, sediada em Manaus-AM, na Rua Igarapé do Mauá, 1, CEP 69075-291, foi fundado no dia 12 de outubro de 1996, no bairro Mauazinho, atuando no ramo de Serviço de Proteção à criança e Adolescente de 0 a 18 anos, buscando atendar a cidade de Manaus e a região.

A principal atividade da entidade é oferecer acolhimento para crianças e adolescentes de forma provisória, oferecendo melhores condições emocionais e de desenvolvimento para o acolhido através de fomentos, emendas e, sobretudo, doações de pessoas sensíveis às necessidades do abrigo.

\section{RESULTADOS E DISCUSSÕES}

Com base nos estudos realizados na etapa do diagnóstico organizacional, foi constatado que a entidade possui diferentes graus de desempenho em seus pontos fundamentais, fato de suma importância para a sustentação funcional da organização, conforme demonstrado no Gráfico 01: Medição de desempenho.

RC: 99485

Link de acesso:

https://www.nucleodoconhecimento.com.br/administracao/implementacao-de- 
Gráfico 01: Medição de desempenho

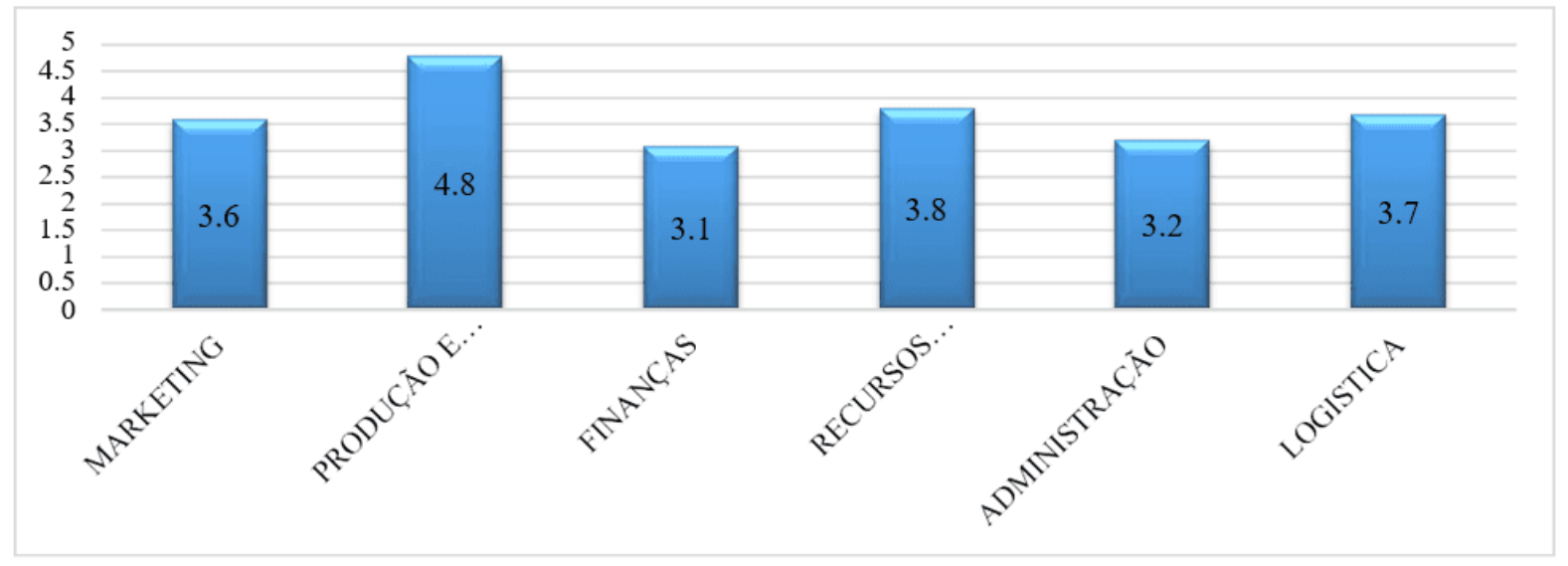

Fonte: Elaborado pelas autoras com base na coleta de dados, 2021.

Conforme aponta o resultado apresentado, nota-se que a entidade possui na área Operacional e de Recursos Humanos seus melhores desempenhos. Já os setores de Logística, Marketing e Administrativo revelam desempenhos médios e, por último, o setor de Finanças é a área que precisa ser melhorada diante dos dados.

Quadro 01: Finanças

ÁREA FUNCIONAL

FINANÇAS
NíVEL OU GRAU DE AVALIAÇÃo

\begin{tabular}{|c|c|c|c|c|}
\hline $\begin{array}{l}\text { Ponto } \\
\text { muito } \\
\text { forte } \\
5\end{array}$ & $\begin{array}{l}\text { Ponto } \\
\text { forte } \\
4\end{array}$ & $\begin{array}{l}\text { Ponto } \\
\text { médio } \\
3\end{array}$ & $\begin{array}{l}\text { Ponto } \\
\text { fraco } \\
2\end{array}$ & $\begin{array}{l}\text { Ponto } \\
\text { muito } \\
\text { fraco } \\
1\end{array}$ \\
\hline & & $x$ & & \\
\hline & & $x$ & & \\
\hline
\end{tabular}

RC: 99485

Link de acesso:

https://www.nucleodoconhecimento.com.br/administracao/implementacao-deestrategias 


\begin{tabular}{|c|c|c|c|c|c|c|}
\hline & $\begin{array}{l}\text { organização } \\
\text { em si }\end{array}$ & & & & & \\
\hline 3 & $\begin{array}{l}\text { O resultado obtido no mês está } \\
\text { sendo do agrado da organização }\end{array}$ & & & $\mathrm{x}$ & & \\
\hline 4 & $\begin{array}{l}\text { A rentabilidade da organização está } \\
\text { tendo resultado positivo no mês }\end{array}$ & & & $x$ & & \\
\hline 5 & $\begin{array}{l}\text { Os demonstrativos } \\
\text { financeiros/informações estão } \\
\text { sempre em evolução positiva }\end{array}$ & & & $\mathrm{x}$ & & \\
\hline 6 & $\begin{array}{l}\text { A organização consegue atender a } \\
\text { quantidade e complexidade com o } \\
\text { Comprometimento fiscal e tributário } \\
\text { exigidos em lei }\end{array}$ & & & $x$ & & \\
\hline 7 & Análise de Investimento VPL/TIR & & & $x$ & & \\
\hline 8 & Transparência nos resultados & & & $\mathrm{x}$ & & \\
\hline 9 & $\begin{array}{l}\text { Os métodos inseridos para o } \\
\text { gerenciamento de riscos estão } \\
\text { sendo bastante viável }\end{array}$ & & & $\mathrm{x}$ & & \\
\hline 10 & $\begin{array}{l}\text { Possui reconhecimento por } \\
\text { excelência financeira de forma direta } \\
\text { ou indireta }\end{array}$ & & $x$ & & & \\
\hline \multicolumn{2}{|c|}{ TOTAL $(\Sigma)$} & 0 & 4 & 27 & 0 & 0 \\
\hline \multicolumn{2}{|r|}{ MÉDIA POR GRAU (POR COLUNA) } & 0 & 0,4 & 2,7 & 0 & 0 \\
\hline \multicolumn{2}{|r|}{ DESEMPENHO DA ÁREA ( $\Sigma$ ) TOTAL } & \multicolumn{5}{|c|}{3,1} \\
\hline
\end{tabular}

Fonte: Elaborado pelas autoras com base na coleta de dados, 2021.

Conforme os fatores críticos apresentados no Quadro 01, observam-se itens fundamentais na área de Finanças no abrigo Lar Batista Janell Doyle que são de grande importância para o rendimento deste. Contudo, é necessário fazer um 
planejamento para trabalhar a questão sobre a captação de renda. Deste modo, o problema da pesquisa consiste em: Como a captação de recursos pode colaborar com as organizações sem fins lucrativos?

\subsection{PLANEJAMENTO DE AÇÕES INTERVENTIVAS}

Planejamento de ação é uma aquisição de melhoria para a organização, criando metas e desenvolvendo objetivos ou atividades para que os encarregados possam verificar o andamento do projeto.

Quadro 02: Ações Interventivas

\begin{tabular}{|c|c|c|c|c|}
\hline Item & Ação Interventiva & Cronologia & Duração & Custo \\
\hline 1. & $\begin{array}{l}\text { Implementar o setor de } \\
\text { Telemarketing }\end{array}$ & Setembro/2021 & 02 meses & $\mathrm{R} \$ 1.260,00$ \\
\hline 2. & $\begin{array}{l}\text { Proporcionar uma Jornada } \\
\text { Científica }\end{array}$ & Outubro/2021 & 02 dias & $\mathrm{R} \$ 500,00$ \\
\hline 3. & $\begin{array}{l}\text { Implementar um Brechó } \\
\text { Simbólico }\end{array}$ & Outubro/2021 & 03 dias & $\mathrm{R} \$ 350,00$ \\
\hline 4. & $\begin{array}{l}\text { Proporcionar um Evento } \\
\text { Beneficente }\end{array}$ & Novembro/2021 & 01 dia & $\mathrm{R} \$ 300,00$ \\
\hline \multicolumn{4}{|l|}{ Total } & $\mathrm{R} \$ 2.410,00$ \\
\hline
\end{tabular}

Fonte: Elaborado pelas autoras da pesquisa, 2021.

A descrição da proposta de solução de cada etapa foi criada por meios dos quadros $5 \mathrm{w} 2 \mathrm{~h}$. Tal ferramenta da qualidade nos permite encontrar as falhas que impedem 0 término adequado do processo, visando a responder as setes perguntas fundamentais, apresentadas posteriormente.

RC: 99485

Link de acesso:

https://www.nucleodoconhecimento.com.br/administracao/implementacao-deestrategias 
Para Neto (2015), a ferramenta 5W2H se torna muito eficaz para o desenvolvimento no plano de ação, pois aponta cronogramas e prazos responsáveis por cada tarefa, recursos financeiros e humanos. Este modelo de ferramenta atinge uma completa abordagem nos objetivos e metas de maneira organizada e direta. Para que as atividades sejam executadas com clareza por todos os envolvidos no plano de ação, a metodologia da ferramenta será utilizada na avaliação e no acompanhamento dos projetos. Através das respostas dos sete pontos dos 5 W's e os $2 \mathrm{H}$ 's, o plano de ação poderá ser traçado de forma prática e coerente, estabelecidos no planejamento orçamentário e estratégico.

\subsubsection{IMPLEMENTAR O SETOR DE TELEMARKETING}

Para demonstrar-se a praticidade do projeto, será necessária a implementação de um setor de Telemarketing, juntamente com a tabela das sete perguntas dos 5 W's e os $2 \mathrm{H}$ 's, no intuito de que haja uma aprovação dos responsáveis pelo setor de RH em relação aos métodos utilizados. Desta forma, será possível iniciar-se a busca pela captação de recursos financeiros para o local, incluindo também a sociedade na superação das necessidades do abrigo, alcançando-se o melhor regulamento para cada processo de implementação estabelecido.

Quadro 03: 5w2h - Implementar o setor de Telemarketing

Implementar o setor de Telemarketing

O quê? Implementar o setor de Telemarketing.

Por quê? Para captar recursos financeiros.

Onde? No Abrigo Lar Batista Janell Doyle.

Quando? Na primeira semana de Setembro de 2021.

Quem? Departamento de RH

Através de uma reunião com os responsáveis pelo setor de $\mathrm{RH}$, a fim de

Como? implementar o setor de Telemarketing, onde ocorrerá a arrecadação de fundos para o abrigo.

RC: 99485

Link de acesso:

https://www.nucleodoconhecimento.com.br/administracao/implementacao-de- 
Quanto? $\mathrm{R} \$ 1.260,00$.

Fonte: Elaborado pelas autoras da pesquisa, 2021.

Conforme enunciado no quadro 3 , de forma geral, a organização está com dificuldades para obter recursos financeiros capazes de suprir a necessidade da instituição. A partir de tal circunstância, tornou-se necessário implementar a ferramenta de telemarketing com objetivo de arrecadar fundos por meio de ações viáveis.

\subsubsection{PROPORCIONAR UMA JORNADA CIENTÍFICA}

Aplicar este item proporcionará inúmeros benefícios para o abrigo, tais como: realização de palestras para os profissionais da área, capazes de abordar diversos temas sobre como o assistente social deve atuar no combate ao abandono, a violência contra crianças e adolescentes.

As inscrições poderão ser feitas por meio de plataformas digitais, tendo um valor simbólico para os estudantes e profissionais. No final, serão entregues os certificados para os participantes. Esta jornada é voltada para a divulgação do Abrigo, mostrando as ações realizadas durante $o$ ano.

Quadro 04: 5w2h - Proporcionar uma Jornada Científica

Proporcionar uma Jornada Científica

O quê? Proporcionar uma Jornada Científica.

Para que os estudantes e profissionais da área, consigam aprimorar

Por quê? seus conhecimentos e que o abrigo seja reconhecido, além de obter

Onde? No Abrigo Lar Batista Janell Doyle.

Quando? Na primeira semana de Outubro de 2021.

Quem? Departamento de RH

RC: 99485

Link de acesso:

https://www.nucleodoconhecimento.com.br/administracao/implementacao-deestrategias 
Como?

Através de palestrantes com experiência, capazes de contar a realidade dessa profissão, e que podem fazer a diferença na vida de crianças e adolescentes.

Quanto? $\mathrm{R} \$ 500,00$.

Fonte: Elaborado pelas autoras da pesquisa, 2021.

Propor uma jornada científica movimentará a organização, trazendo o benefício de palestras educativas com profissionais da área, abordando diversos temas pertinentes da área de Assistência Social, oferecendo mais conhecimento aos estudantes e profissionais, além de fomentar vários eventos capazes de promover arrecadação de fundos.

\subsubsection{IMPLEMENTAR UM BRECHÓ SIMBÓLICO}

Traçar um evento será outro meio de captação, o qual ocorrerá três vezes ao ano no centro da cidade, com preços bastante acessíveis, a partir de $R \$ 5,00$. Tal ação possuirá um fator importante para a Instituição: além do abrigo arrecadar boas peças para a venda, também terá como brinde: chaveiros, agendas, canetas e camisetas, levando a marca do abrigo para a divulgação externa.

Quadro 05: Implementar um Brechó Simbólico

Implementar um Brechó Simbólico

O que? Implementar um Brechó Simbólico.

Por quê? Para que o abrigo obtenha uma renda extra com as vendas

Onde? No centro da Cidade de Manaus.

Quando? Na terceira semana de Outubro de 2021.

Quem? Os colaboradores do Abrigo

Como? Através das vendas de vestimentas e calçados com boa aparência e que no ato da finalização da compra, o cliente recebe o brinde levando a 
marca do abrigo.

Quanto? R\$350,00

Fonte: Elaborado pelas autoras da pesquisa, 2021.

Empregar esta ação poderá contribuir com uma renda extra para o abrigo, pois, como será feito em três dias e terá peças acessíveis, voltadas principalmente para as crianças, sua renda poderá ser utilizada para repor o estoque em suprimentos como: alimento, materiais de higiene pessoal e medicamentos, além de contribuir para o fechamento do caixa, proporcionando um valor maior que o investido.

\subsubsection{PROPORCIONAR UM EVENTO BENEFICENTE}

Promover este último item poderá obter um retorno financeiro deveras significativo para o Abrigo. Neste evento, será oferecido um serviço gastronômico, com a presença de alguns chefes conhecidos pela cidade de Manaus, os quais demonstrarão seus cardápios mais famosos, além da música ao vivo e da programação especial para crianças, contando com brincadeiras e atividades promovidas por animadores infantis.

Contudo, devido às questões sanitárias, o evento será de até $50 \%$ (cinquenta por cento) da capacidade permitida, com equipes controlando a entrada e saída do local, além do fornecimento de álcool em gel disponível para o público. O evento será feito no SESI - Clube do Trabalhador.

Quadro 06: Proporcionar um Evento Beneficente

Proporcionar um Evento Beneficente

O quê? Proporcionar um Evento Beneficente.

Por quê? Para que o arrecadamento seja usado para as melhorias do abrigo.

Onde? No SESI - Clube do Trabalhador.

Quando? Na primeira semana de Novembro de 2021.

RC: 99485

Link de acesso:

https://www.nucleodoconhecimento.com.br/administracao/implementacao-de- 
Quem? Os colaboradores do Abrigo.

Através das presenças dos chefes mais conhecidos de Manaus, além de promover música ao vivo, contando com programação especial para

Como? as crianças, contudo, dentro das normas de capacidade permitida.

Quanto? $\mathrm{R} \$ 300,00$.

Fonte: Elaborado pelas autoras da pesquisa, 2021.

Realizar essa ação poderá colaborar com resultados positivos não somente na questão da captação de renda para melhorar o fluxo de caixa, mas também para a divulgação do trabalho do Abrigo, disseminando pela cidade sua jornada até o presente momento, sua significatividade e representação local, possibilitando a entrada de mais voluntários e projetos capazes de auxiliar no desenvolvimento social das crianças e adolescentes que dependem da Instituição.

\section{CONSIDERAÇÕES FINAIS}

O Abrigo Lar Batista Janell Doyle possui serviço de acolhimento de diferentes faixas etárias segue com seus quatros segmentos, (família acolhedora, acolhimento institucional, moradores de rua e fortalecimento de vínculo com as famílias da comunidade) ao longo destes 25 (vinte e cinco) anos onde a unidade está localizada, oferecendo ferramentas para que as pessoas resinifiquem a vida. $A$ pesquisa obteve-se como objetivo investigar através de dados coletados e atualizados, a avaliação administrativa e financeira do abrigo Lar Batista Janell Doyle. Para que seja um ambiente além de acolhedor e com estrutura adequada tanto interna quanto externa, para atender às necessidades de cada indivíduo acolhido, é preciso que o local os forneça condições de acessibilidade, alimentação, requisitos favoráveis a saúde, higiene, proteção integral, privacidade ou até mesmo vestimentas para crianças e adolescentes que necessitam em prol de valores sociais.

RC: 99485

Link de acesso:

https://www.nucleodoconhecimento.com.br/administracao/implementacao-deestrategias 
Destaca-se o presente estudo de caso, realizado através da seguinte pergunta problema: como a captação de recursos pode colaborar com as organizações sem fins lucrativos? Onde foi detectado a importância da Gestão Financeira, sobre a melhoria dos aspectos ligados aos problemas de controle de finanças, haja métodos simples e planejamentos estratégicos a serem discutidos para um crescimento saudável na organização, clareza sobre negócios e assim conseguir uma melhor tomada de decisões para atender suas respectivas demandas.

Verificou-se que mediante dos resultados obtidos, perante as implementações do conjunto de ações para ocorrer a captação de recursos para o Lar, será de grande ajuda para que o setor financeiro possa ter o seu rendimento favorável. Sendo assim, os resultados foram satisfatórios, pois o conjunto de ações especificados no decorrer do artigo, obteve-se com o intuito de prover as necessidades em questão. Deste modo, constatamos que a gestão orçamentária do abrigo deve analisar não somente os impactos nas decisões e quadros operacionais, mas igualmente nas políticas necessárias de financiamentos e investimentos a médio ou longo prazo, para a continuidade da organização e sua sustentabilidade.

Conclui-se através do diagnóstico no qual aponta com uma movimentação financeira positiva e juntamente profissionais competentes na área de gestão empresarial e orçamentária, a entidade se tornará capaz de pagar salários, fornecedores e manter com tranquilidade as atividades mensais e anuais. Sugere-se, treinamentos contínuos para seus funcionários em geral para maior disposição em todos os setores e que o trabalho também os motive, tornando a responsabilidade conjunta, ideias inovadoras e trabalho favorável e efetivo.

\section{REFERÊNCIAS}

APPOLINÁRIO, Fábio. Dicionário de Metodologia Científica. $2^{\underline{a}}$ ed. São Paulo: Atlas, 2011. 
ARAGÃO, José Euzébio de Oliveira Souza; FILHO, Edmundo Escrivão. Introdução à Administração: desenvolvimento histórico, educação e perspectivas. $1^{\underline{a}} \mathrm{ed}$. São Paulo: Atlas, 2016.

AZEVEDO, Celicina Borges. Metodologia científica: ao alcance de todos. $3^{\text {a }}$ ed. São Paulo: Manole, 2013.

BRIGHAM, Eugene F.; EHRHARDT, Michael C. Administração financeira: teoria e prática. $3^{\underline{a}}$ ed. São Paulo: Cengage Learning, 2016.

CHIAVENATO, Idalberto. Gestão financeira: uma abordagem introdutória. $3^{a} \mathrm{ed}$. São Paulo: Manole, 2015.

COOPER, Donald R.; SCHINDLER, Pamela S. Métodos de pesquisa em administração. 12 $2^{\mathrm{a}}$ ed. Porto Alegre: AMGH, 2016.

GILLESPIE, Andrew.; MARCOUSÉ, lan; SURRIDGE, Malcolm. Administração série processos gerenciais. $1^{\text {a }}$ ed. São Paulo: Saraiva, 2013.

GITMAN, Lawrence J. Princípios de administração financeira. 12ª ed. São Paulo: Pearson Prentice Hall, 2010.

KWASNICKA, Eunice Lacava. Introdução à Administração. 6 6 $^{\text {a }}$ ed. São Paulo: Atlas, 2012.

LAKATOS, Eva Maria; MARCONI, Marina de Andrade. Fundamentos de metodologia científica. 9ª ed. São Paulo: Atlas, 2021.

LIBÓRIO, Daisy; TERRA, Lucimara. Metodologia científica. São Paulo: Rede Internacional de Universidades Laureate, 2015.

LIMA, Fabiano Guasti; NETO, Alexandre Assaf. Curso de administração financeira. 4ª ed. São Paulo: Atlas, 2019.

RC: 99485

Link de acesso:

https://www.nucleodoconhecimento.com.br/administracao/implementacao-deestrategias 
LOBO, Renato Nogueirol. Gestão da qualidade. $2^{\underline{a}}$ ed. São Paulo: Érica, 2020.

MAXIMIANO, Antônio Cesar Amaru. Introdução à Teoria Geral da Administração. $3^{\underline{a}}$ ed. São Paulo: Atlas, 2015.

NETO, Alber. Metodologia Laila: guia de etapas e ferramentas para concepção de projetos centrados no ser humano. Campos de Goytacazes, 2015.

NUNES, Karina da Silva; LOZADA, Gisele. Metodologia científica. Porto Alegre: Sagah, 2018.

OLIVEIRA, Ricardo da Cunha. Administração Financeira: uma análise conceitual. 2016. Disponível em: <https://portal.estacio.br/media/6085/10administra\%C3\%A7\%C3\%A3o- financeira-uma-an\%C3\%A1 lise-conceitual.pdf> .Acesso em 04 de setembro de 2021.

PALADINI, Edson Pacheco. Gestão da qualidade: teoria e prática. $4^{a}$ ed. São Paulo: Atlas, 2019.

PASSARLE, Roberto. Gestão: ferramentas da qualidade. $1^{a}$ ed. São Paulo: Senai, 2014.

PEREIRA, José Matias. Manual de metodologia da pesquisa científica. $4^{\mathrm{a}}$ ed. São Paulo: Atlas, 2019.

ROSS, Stephen A. Administração financeira. 10ª ed. Porto Alegre: AMGH, 2015.

SANTANA, F.M. O fluxo de caixa como ferramenta do controle financeiro nos micros e pequenas empresas. Viçosa-MG, 2013.

SEVERINO, Antônio Joaquim. Metodologia do trabalho científico. $2^{\mathrm{a}}$ ed. São Paulo: Cortez, 2017.

RC: 99485

Link de acesso:

https://www.nucleodoconhecimento.com.br/administracao/implementacao-deestrategias 
SILVA, Paula do Vale. Análise da administração de capital de giro como instrumento de apoio a gestão. Viçosa-MG, 2015.

SORDI, José Osvaldo de. Gestão por processos: uma abordagem da moderna administração. 5ำ ed. São Paulo: Saraiva Educação, 2018.

SOUZA, Acilon Batista de. Curso de administração financeira e orçamento: princípios e aplicações. São Paulo: Atlas, 2014.

VERGARA, Sylvia Constant. Métodos de pesquisa em administração. $6^{a}$ ed. São Paulo: Atlas, 2015.

WALLIMAN, Nicholas. Métodos de pesquisa. $1^{\text {a }}$ ed. São Paulo: Saraiva, 2015.

ZANELLA, Liane Carly Hermes. Metodologia de Pesquisa. $2^{\underline{a}}$ ed. Florianópolis: UFSC, 2013.

Enviado: Outubro, 2021.

Aprovado: Outubro, 2021.

RC: 99485

Link de acesso:

https://www.nucleodoconhecimento.com.br/administracao/implementacao-deestrategias 